\title{
FILOSOFÍA Y CIENCIA EN EL PENSAMIENTO REACCIONARIO ESPAÑOL DURANTE LA II REPÚBLICA. LA FIGURA DE JOSÉ PEMARTÍN
}

\author{
PHILOSOPHY AND SCIENCE IN SPANISH \\ REACTIONARY THOUGHT DURING THE SECOND \\ REPUBLIC. JOSÉ PEMARTIN'S IMAGE
}

Álvaro CASTRO SÁNCHEZ ${ }^{*}$

UNED

\begin{abstract}
RESUMEN. La relación de la Filosofía con las ciencias y en concreto, con los avances de la física moderna y las matemáticas de comienzos del siglo $\mathrm{XX}$, ha sido uno de los rasgos característicos de algunas de las mejores carreras filosóficas españolas, comenzando por la obra de Ortega y Gasset o Zubiri. Pero las preocupaciones que los nuevos descubrimientos suscitaron, desde sus implicaciones ontológicas hasta el rango mismo del pensamiento filosófico respecto a otros saberes, también fueron objeto de reflexión para pensadores tradicionalistas o semireaccionarios vinculados a la Iglesia o a los grupos y partidos autoritarios que provocarán la Guerra Civil y ocuparán los primeros puestos de la filosofía académica en los años cuarenta. Aquí estudiaremos el caso concreto del filósofo José Pemartín durante los años previos a la guerra, cuando trató problemas centrales de la Filosofía y la Ciencia de su tiempo y esbozó una ontología de lo temporal como respuesta.
\end{abstract}

*

Dirección postal: Calle Arenillas 7, casa 2, 14002 - Córdoba. alvaroc.s@hotmail.es

ENDOXA: Series Filosóficas, $n^{\circ}$ 32, 2013, pp.133-152. UNED, Madrid 
PALABRAS ClAVE: Pemartín, filosofía española, Ciencia, pensamiento reaccionario, Segunda República.

ABSTRACT. The relationship between philosophy and sciences, regarding the advances of modern Physics and Mathematics in the early twentieth century, has been one of the characteristic features of some of the better Spanish philosophical careers, like the work of Ortega y Gasset or Zubiri. But the concerns that provoked new discoveries -in relation to its ontological implications and the importance of philosophical thought compared to other knowledge-, were also under consideration for traditionalist thinkers or half-reactionaries connected with the Church or authoritarian groups and parties, which will cause the Spanish Civil War and will take up the first positions in academic philosophy in the 40's. We will study the case of philosopher José Pemartín during the years before the war, when he dealt with central problems of Philosophy and Science of his time and outlined an ontology of temporality like as an answer.

KEYWORDS: Pemartín, Spanish philosophy, Science, reactionary thought, Second Republic

\section{Introducción}

Aunque la Historia de la Filosofía ha sido una materia o área de conocimiento privilegiada en la filosofía académica española, caracterizada por la extendida dedicación al comentario de textos clásicos o de autores del ámbito filosófico internacional, el diálogo entre Filosofía y Ciencia cuenta con una larga tradición en España durante el siglo XX y ha marcado algunas de sus trayectorias más creativas. Por ejemplo, conocida es la preocupación de la Institución Libre de Enseñanza y de figuras como Ortega y Gasset por la Ciencia (Zamora, 2005), de tal modo que el diálogo con las ciencias naturales y sociales fue un rasgo compartido del orteguismo y la Facultad de Filosofía de Madrid a comienzos de la II República, representado por catedráticos como Xavier Zubiri, Julián Besteiro o Juan Zaragüeta, o con la implicación de García Morente y el propio Ortega en editoriales como Espasa-Calpe, que puso en circulación un gran conjunto de obras de referencia de diferentes ramas científicas desde los años veinte. Para los herederos de la llamada “Generación del 14”, el conocimiento científico era indispensable para conocer mejor al ser humano y su realidad, y para resolver los 
problemas particulares de España, a la vez que obligaba a repensar el lugar mismo de la Filosofía en un momento de crisis respecto a su puesto en el orden de los saberes. Pero estas preocupaciones no fueron exclusiva de las tradiciones de pensamiento liberales o racionalistas que van a quedar truncadas en 1936, porque también las compartió una parte de los intelectual ligados a la Iglesia y al catolicismo social desde comienzos de siglo, y fueron foco de atención para pensadores de corte tradicionalista o semireaccionario que también tenían sus propios planes para la modernización de España. Es más, los modos de abordar las cuestiones científicas de los intelectuales hostiles a la democracia y al socialismo entonces fueron los que se impusieron en los 1940, y algunas de sus orientaciones básicas van a condicionar las primeras delineaciones de la Filosofía de la Ciencia como área específica a finales de esa década (Vázquez, 2013).

Sin embargo, ha sido perspectiva historiográfica habitual la idea de que la Filosofía de la Ciencia en España no merece tal calificativo hasta la aparición de la revista Theoría en 1953 en el seno de la Sociedad Española de Filosofía, y salvo contados trabajos, se desconocen las condiciones y líneas de reflexión que hicieron posible la aparición de esta, así como las redes intelectuales que trataron más allá de la de Ortega temas científicos desde un punto de vista filosófico o se preocuparon por conocer e importar epistemologías de otros países con anterioridad a la Guerra Civil y durante la inmediata posguerra. Además, también falta investigación acerca de cómo nuevas problemáticas filosóficas, sobre todo ante el terremoto causado por la Física y Matemática desde los años veinte, eran leídas y tratadas en el sub-campo intelectual del pensamiento reaccionario español, que cuenta con una propia y singular tradición.

En este trabajo se aborda un periodo concreto -el de la II República- de la producción teórica de un pensador desconocido como fue el jerezano José Pemartín y Sanjuán (1888-1954), cuya obra y labor de articulista tiene un sitio específico en el pensamiento español de los años treinta y cuarenta, sobre todo por su incidencia directa en los acontecimientos políticos que marcaron su tiempo (Quiroga, 2008). Se trata de hacer con esto una aportación concreta respecto a un intelectual cuya carrera merece mayor atención que la que ha recibido al menos desde la perspectiva de una historia de la filosofía española que abandone la ideología del genio filosófico y se ponga en diálogo 
con la historia, ya que por ejemplo la labor de Pemartín es central en la configuración de la cultura franquista a través de su sistema de enseñanza; abrir además nuevas perspectivas para el estudio del tratamiento de la relación entre Filosofía y Ciencia en un periodo marcado por la cruzada anti-modernista de la Iglesia, cuestión que generó algunas de las mejores trayectorias filosóficas de la segunda mitad de siglo; y por último, analizar cómo resonaban en la figura de un intelectual orgánico de la aristocracia rural andaluza y de la extrema derecha española los problemas propios de la filosofía y la física-matemática de su tiempo. Se trata entonces de hacer no solamente una lectura de los textos de Pemartín, sino también un análisis de sobre cómo un pensador menor predispuesto por una orientación ideológica concreta lee los textos de filósofos consagrados, los interpreta y retraduce para la reproducción de su propio mundo social, formado por la aristocracia española, el funcionariado conservador, militares africanistas y los sectores más clericalizados de la sociedad; público que además se apropia de sus conceptos clave, que interpreta desde su particular visión del mundo y los aplica con más normalidad de lo que se cree en su representación cotidiana de los acontecimientos sociales y políticos. Se parte de la premisa metodológica de que sin una historia de sus lecturas y de las apropiaciones cotidianas de las mismas no es posible hacer una historia de la filosofía -o de los clásicos- reflexiva y generadora de conocimiento histórico.

\section{Filosofía, Ciencia y pensamiento semi-reaccionario antes de la Guerra Civil}

Desde los años veinte venía dándose una creciente reflexión filosófica acerca de la ciencia desde diferentes focos. Uno estaba compuesto por físicos y matemáticos como Blas Cabrera o Rey Pastor, los cuales eran dados a tener presencia de filósofos en sus aulas de la Universidad de Madrid, como fue el caso de Zubiri (Corominas 2006, 160). Otra línea sería la de los lógicos, cuyos mejores representantes eran García Bacca y Julián Besteiro. Por último, los filósofos influidos por Husserl y la revolución de la física a partir de Einstein, entre los que destacarán Ortega y Zubiri.

Por su parte, desde los tiempos de la condena del Vaticano al modernismo religioso (1907), algunos sectores dentro de su aparato educativo habían tomado 
conciencia de la necesidad de formar sacerdotes dotados de un capital filosófico y científico actualizado, privilegiando los conocimientos de física, matemáticas y biología, algo por lo que se preocuparon figuras como el influyente sacerdote Domingo Lázaro que orientó pedagógicamente a los Colegios Marianistas y fundó la Federación de Amigos de la Enseñanza, de la que Pemartín será presidente-. Integrar las nuevas teorías científicas en el marco de la filosofía aristotélico-tomista era el objetivo de la Universidad de Lovaina y el Cardenal Mercier que para España trasladó Juan Zaragüeta, otro sacerdote autor de una interpretación en clave tomista del bergsonismo (Lacau ST Guilly 2010, 375-381). El objetivo general era defender la primacía de la Filosofía frente a la Ciencia y con ello, acabar disolviendo ambas en el dogma de la ortodoxia católica. El enemigo a batir era el positivismo.

Carreras como las de Zubiri o García Bacca son un ejemplo de lo importante que fue esta orientación. Zubiri, guiado en un primer momento por Domingo Lázaro y Zaragüeta (Corominas 2006, 67), caracterizó su carrera por la ambición de reconciliar las ciencias contemporáneas con el realismo crítico, no abandonando nunca, a pesar de sus múltiples ajustes terminológicos y deslizamientos semánticos esa apuesta -que sigue latiendo en su reflexión madura sobre la inteligencia sentiente y la religación-. Por su parte, García Bacca recordará en su auto-biografía cómo debía aprender y recitar la geometría de Euclides de memoria en el Seminario de los Padres Claretianos donde realizó sus primeros estudios de Filosofía y Teología (García Bacca 2000, 14-28). Fue en sus crudos años de noviciado donde se le despertó el gusto por las matemáticas y la física, gracias a las cuales aguantaba el aburrimiento de la Teología moral y de la insistencia en el sexto mandamiento. Ambos pasaron por Lovaina y además ampliarán estudios en Alemania, el primero en Friburgo, Munich y Berlín con Sommerfeld, Heisenberg, Einstein o Schrödinger, y el segundo entre 1928 y 1931 en Munich con Sommerfeld y Perron. Zubiri mantendrá el diálogo con las ciencias naturales y las matemáticas toda su vida, mientras que García Bacca, más oscilante, en los años treinta publicará obras elogiadas por Pemartín como Introducción a la logística (1934) e Introducción a la lógica moderna (1936), teniendo como base la tesis doctoral realizada en Barcelona sobre la estructura lógico-genética de las ciencias físicas. Desde entonces, 
los diferentes pasos que irá dando la ciencia moderna se le convirtieron en choques definitivos para el mantenimiento de la fe y del "fondo aristotélico-tomista" de su filosofía (García Bacca 2000, 119-137).

En el caso de Zubiri otro punto de partida para la incorporación de la necesidad de atención a la ciencia para su carrera filosófica lo tuvo en Ortega, quien en El Tema de nuestro tiempo (1923) anunció para el campo filosófico español la quiebra de la razón positivista y del proyecto cartesiano. Para Ortega, como después para Zubiri, la ciencia moderna arranca con Descartes y su "entusiasmo por las construcciones de la razón" (Ortega 1923/2006, 94), que reducía la perspectiva natural sobre la realidad a mera sucesión y cantidad. La razón moderna es incapaz de manejar las cualidades, que quedan relegadas al ámbito de lo irracional, y solamente contempla como construcción "a priori” las propiedades cuantitativas de las cosas. Por ello se caracteriza el positivismo cientificista, no por el respeto a los hechos. Esa distinción entre lo cualitativo y lo cuantitativo tomada de Ortega -que este recoge a su vez de los debates epistemológicos europeos de primeros de siglo- y pronto convertida en todo un tópico de larga sombra será fundamental para Pemartín, que unirá a ese mismo diagnóstico del fracaso de la razón moderna el de la Ilustración y los ideales democráticos. De una fortísima fe religiosa que mantiene hasta su muerte en 1954, ¿en qué matriz ideológica y contexto filosófico inmediato se movía Pemartín?.

Para Zaragüeta, que lideró el viraje conservador de la Asociación Española para el Progreso de las Ciencias a finales de los años veinte (García 1993, 49-81), la formación científica tenía que estar supeditada a la moral, y era esta la verdadera reforma que necesitaba España, de ahí su valoración positiva, también muy presente en Pemartín, de la obra de Max Scheler. La axiología justificaba deslindar al pensamiento de su vínculo con la verdad reconociendo que también es propio de aquel la atención a otros valores que escapan a la racionalidad (Zaragüeta 1934, p. 31): “¿qué de extraño tiene, después de todo, que el hombre (...), pese a su consabida definición de animal racional, se rija de hecho por una ley alógica y vital substratum de otra lógica y racional?”. A este filósofo le interesaba precisamente la psicología -obtuvo la cátedra en la Universidad de Madrid en 1932- porque atiende al aspecto vital de la mentalidad. La función de la filosofía es 
“racionalizar la vida”, pero la extrema racionalización filosófica o científica tiene en su contra (1934, p. 41) "todo lo que hay de contingente y de personal en la constitución de la Naturaleza física, en la estructura del espíritu humano y en la fisonomía de la Historia”. La extrema racionalización de la vida conlleva su paralización, pero también sería de rechazar una abdicación de la razón frente a los impulsos totalitarios de la naturaleza; de ahí la necesidad del cultivo de la virtud y de los valores morales por los que vigila la Iglesia. Y dichos valores se asientan en la realidad cualitativa, temporal y espiritual de la persona. En ese sentido Zaragüeta (1963, p. 111) era optimista, pues "puede decirse que asistimos actualmente a una completa restauración de la heterogeneidad cualitativa a todo lo largo de la experiencia filosófica". En dicho supuesto viraje hacia lo cualitativo que puede re-situar a la metafísica especial atención debía de tener el concepto de tiempo (1963, p. 141-179). En este ámbito ideológico del que participa Pemartín, que colaborará con Zaragüeta a partir de la Guerra Civil, el uso habitual de esta categoría en dependencia de la de espacio o "tiempo espacializado" se importa de Poincaré y Bergson. Para este, a cuyos cursos en el Cóllege de France el jerezano había asistido a comienzos de siglo, el "tiempo viviente" no es una sucesión de momentos que van de un punto a otro, tiempo que no puede medirse, por tanto, en términos de cantidad. Para un pensamiento impregnado por la confianza en la providencia como era entonces el de Pemartín, será lo intenso o cualitativo, asimilado a lo espiritual, la puerta de entrada de lo divino en la historia.

\section{La Física y el Espíritu}

Durante el periodo republicano Pemartín, de formación ingeniero y catedrático de francés en Cádiz, encuentra un espacio para mostrar su familiaridad respecto a la filosofía y los temas centrales de la física y las matemáticas de su tiempo en la revista Acción Española, órgano de pensamiento ultra-conservador dirigido por Maeztu y que agrupaba a la extrema derecha alfonsina anti-republicana (González, 1998). Tempranamente, a finales del año 1932 y comienzos de 1933, publicó un artículo en seis entregas bajo el título “La Física y el Espíritu”. En su primera parte estaba dedicado a la obra de W. 
Ostwald (1853-1932), que había fallecido recientemente. Atendía en ella a una problemática fundamental de los inicios del siglo veinte para la Filosofía de la Ciencia en ciernes. Desde mediados del siglo XIX se estaba poniendo en duda la naturaleza atómica del mundo físico. Ostwald, muy cercano a la postura de Ernst Mach, con quien compartía la idea de "ficción” de las entidades atómicas, con su obra Más allá del materialismo (1895) se hizo protagonista del enfrentamiento entre atomismo y energetismo a la hora de postular la composición de la materia (Moreno 2006, 24). Para el científico alemán la Energía era una constante ontológica que se transforma en múltiples fenómenos, entre ellos la materia.

Pemartín valora esa defensa de la energía como sustancia prima, que a su vez es actividad única y substrato general del Universo, de tal modo que todos los fenómenos físicos son manifestaciones o formas de energía determinadas por sus intensidades y tienen en común su mensurabilidad matemática (Pemartín 1932a, 28). La historia reciente de la ciencia se caracterizaba para el jerezano por un severo avance del "a priori” físicomatemático kantiano, pues se había ascendido un camino desde los juicios sintéticos “a priori” hasta la fundamentación de todo conocimiento físico en puros principios lógicos, siendo esa la dirección de Hilbert, Russell o Poincaré. Ostwald, como kantiano, abría la posibilidad de diferenciar entre una realidad energética cualitativa o intensa y una razón cuantitativa que construye “a priori” la interpretación de los fenómenos. Aún así, no aceptaba su monismo energetista cuando este se aplicaba a la realidad humana, porque del hecho de que existan correlaciones entre fenómenos energéticos y psíquicos no se deduce que los segundos, que Pemartín entiende como procesos espirituales, sean fenómenos físicos. Bergson, en L'évolution Créatrice (1907) ya había señalado que la ley en la que Ostwald apoyaba su síntesis ontológica, la Ley de la Degradación de la energía, era una mera generalización metafísica (Bergson 1907/1973, 216-217). Al confundir relación con identidad se aparta de toda una filosofía que individualiza lo psíquico, que es la que va de Bergson a Scheler, línea que en España defiende Zaragüeta. Es por eso que Ostwald era un preso del ochocentismo y por tanto, del naturalismo.

A partir de la tercera entrega de su largo artículo Pemartín somete a crítica la interpretación orteguiana de la física de Einstein. En un ensayo de 1923 Ortega había 
hablado del carácter absolutista en el plano del conocimiento de su física, mientras que en el plano de la realidad demostraba el relativismo. Ese carácter absolutista del conocimiento en Einstein lo desmarcaba de la tradición galileano-cartesiana (Ortega 1923/2006, 186) señalando una incomprensión de la relatividad en aquellos que la hacen derivar del kantismo, pues espacio y tiempo no son fruto de la subjetividad, sino "ingredientes objetivos de la perspectiva física". Esto es, la realidad se da siempre como perspectiva (1923/2006, p. 189), "es el orden y la forma que la realidad toma para el que la contempla”. Así, la perspectiva se antepone a la razón en el plano del conocimiento del mundo físico, con lo que su doctrina del punto de vista quedaba legitimada ontológicamente.

Para Pemartín Ortega comete dos errores: no entendió que la teoría de la relatividad era en realidad una renovación del cartesianismo y además, desfiguraba a la mecánica clásica al hacerla derivar del filósofo francés. Galileo y Newton se encontraron con una Geometría que se ajustaba a las exigencias de sus propias experiencias científicas, mandando estas, por lo que Ortega no tiene en cuenta la raíz empírica de sus desarrollos físicos. Como indica Pemartín, ninguna teoría física hasta el siglo XIX ha tenido una carrera más brillante de confirmación experimental que la física de Newton en su aplicación al desarrollo técnico e industrial. Respecto a Einstein, el valor de su teoría no reside en haber invertido la relación entre razón y observación, ni en haber mostrado que tiempo y espacio sean formas de lo real. Respecto a esto, opone a la reflexión de Ortega la consideración del espacio y el tiempo de su sistema cuatridimensional gaussiano como "privados de su último resto de objetividad física”(Pemartín 1933a, 145). ${ }^{1}$ Einstein no está más allá de Kant como Ortega pretende enfatizando su supuesto anti-racionalismo, sino que los presupuestos filosóficos del alemán los informa el idealismo de origen cartesiano. Para Pemartín existe una corriente implícita de relativismo total en toda la ciencia moderna (Pemartín 1933b, 248), que parte de

1 Como señala Thomas f. Glick, ninguno de los dos captaron correctamente la crítica de Einstein a la observación física y por ende carecía de sentido preguntarse acerca de qué es lo real según el físico alemán, lo que constituye un ejemplo de deslizamiento semántico al trasladar un problema de ciencias a problemáticas filosóficas (Glick, 2005: 244-245). 
Descartes y llega hasta Helmhotz, Mach y Poincaré, y que es la base del relativismo de Einstein -relativismo porque toda interpretación del cosmos se reduce a un punto de vista particular, esto es, el del sujeto según lo entiende la razón físico-matemática moderna, algo en lo que sí coincide con Ortega-. En este punto, se apoya en el debate abierto por Bergson en Durée et simultaneité (1922). En Newton dicho relativismo no estaba presente porque en este prevaleció el pragmatismo y empirismo, y sus conceptos de Espacio, Tiempo o Movimientos absolutos los usaba en sentido contrario a las interpretaciones de Ortega.

A partir de este momento, los restantes capítulos se centran en una exposición sistemática de las aportaciones de Einstein para concluir que su avance metodológico se basa precisamente en haber fundado una nueva objetividad (Pemartín 1933c, 354) que hace converger todas las construcciones de la ciencia de los últimos tiempos en una unidad matemática total, un “cartesianismo definitivo”. Abstrayendo a la Física de todo devenir, biológico o histórico, Einstein acaba convirtiendo el mundo físico en una mens instantánea (Leibniz) fuera del tiempo. En esa matematización nominalista participan todos los demás físicos actuales, desde Louis de Broeglie, Schrödinder y Dirac, a Heisenberg. Algo a destacar aquí es que Pemartín afronta estas problemáticas apoyándose no solamente en Bergson, sino en la epistemología francesa de entonces, en concreto, la encabezada por Brunschvicg (Pemartín 1933c, 241). En efecto, F. Vázquez García (2013, 308-312) ha puesto de relieve cómo Pemartín fue el primer autor español en hablar en España de Gastón Bachelard y por ende, de la tradición francesa de la epistemología histórica, que arrancaría con la escuela convencionalista que representaban Duhem y Poincaré, descollaría con el continuismo histórico de Brunschvicg y Meyerson, y se concretaría con Bachelard, Canguilgem y Cavaillés. ${ }^{2}$

Pemartín valora la capacidad de síntesis creciente del avance científico, pero se para con sus límites y subraya uno evidente en su tiempo: el principio de indeterminación de Heisenberg, auténtico límite interno para la física que en la posguerra el sector clerical

2 Agradezco a Francisco Vázquez García haberme facilitado leer el manuscrito de su trabajo antes de su publicación así como sus comentarios al borrador inicial de este trabajo. 
de la filosofía española explotará sucesivamente. Esa limitación de la razón positivista es la que informa de la necesidad de construir una nueva Metafísica.

\section{Hacia una ontología de lo temporal}

En la primavera de 1936 Pemartín había preparado una serie de 12 sesiones para un curso de verano promovido por Acción Española, las cuales no pudo impartir por la precipitación de los acontecimientos. Estas lecciones fueron recogidas en un volumen con el título Introducción a una filosofía de lo temporal, publicado por primera vez en Sevilla en 1937 y tras la guerra en 1941 por Espasa-Calpe. Este texto es el que mejor expresa su pensamiento en relación a cuestiones científicas y a la filosofía europea de entonces. Sus tesis convergen con toda una teología política que se concretará durante el primer año de la contienda con la publicación de Qué es «lo nuevo» (Sevilla, 1937), cuya contribución al diseño del inmediato estado franquista es muy importante. Aquellas lecciones son una muestra ejemplar de como los problemas fundamentales de la ciencia y de la filosofía eran tratadas en el sub-campo del pensamiento reaccionario español previo a la Guerra Civil en este caso por uno de los elementos más dotados técnica y culturalmente para ello, y de cómo los conceptos filosóficos se deslizan semánticamente cuando se introducen y usan en juegos de lenguaje y mercados de bienes intelectuales y simbólicos distintos. Puestos a disposición en el terreno de la guerra ideológica y de las luchas por la hegemonía entre las distintas familias políticas de la derecha española, los mismos muestran su historicidad.

En su introducción, Pemartín indica la confluencia de tres intereses distintos para la elección del tema en los cursos: la primera sería la revisión las nociones fundamentales de la física que fue comenzada por Poincaré y Duhem; por otro lado, le interesa la orientación temporalista de la filosofía actual, desde Bergson a Heidegger, y por último, su interés por plantear una actitud personal, intelectual y moral ante el Cosmos.

En primer lugar, el curso se organiza mediante el repaso de las concepciones de conceptos fundamentales a lo largo de diferentes hitos de la historia de la filosofía de la ciencia, como en el primer capítulo lo hace con la concepción del Espacio bajo el prisma 
del problema gnoseológico de la consideración objetiva o subjetiva de lo espacial y lo temporal. La solución la indaga Pemartín en la idea de la intencionalidad de la conciencia de Husserl; es dicha intencionalidad la que nos obliga a reconocer los objetos y formas objetivas, aunque se comprenda el Espacio y el Tiempo como vivencia de la conciencia (Pemartín 1941, 12). Del tiempo y la causalidad se ocupa en el capítulo 4. Repasa la noción de Tiempo absoluto en Newton, la Escolástica y Kant, prestando atención crítica a la consideración subjetivista de este porque considera que es en la que se apoya Einstein (Pemartín 1941, 49) y a la que opone la concepción psicológica de Bergson y existencial de Heidegger. Citando a este, analiza su noción de tiempo como éxtasis, lo que le lleva a diferenciar entre el tiempo primordial, puramente cualitativo, que se relaciona con el tiempo psíquico o espiritual; el tiempo mundial, que es de equilibrio entre lo cuantitativo y cualitativo, y el tiempo vulgar o de la existencia banal, donde la cantidad domina sobre la cualidad (1941, p. 54):

El tiempo primordial se temporaliza bajo el aspecto del porvenir y tiene un carácter principalmente ético; el tiempo mundial se temporaliza bajo el aspecto del pasado y tiene un carácter histórico o tradicional; el tiempo vulgar, bajo el aspecto del presente.

La existencia de las personas está condicionada sobre cómo vivan su propio tiempo. La existencia banal es la del presentismo, que no reconoce el valor del pasado y en la que la cantidad predomina sobre la calidad, y que Heidegger denomina como "el se anónimo”. Repitiendo esa forma de argumentar que ya se vio en Zaragüeta, Pemartín se enfrenta a toda visión cuantitativa del Cosmos, cuya última versión, que ha supuesto el agotamiento del pensamiento occidental, es la física de Einstein. Lo cualitativo se constituye por lo temporal y la energía, y por ende, lo espiritual (1941, 160-161). Esta línea argumentativa es el núcleo de su planteamiento ontológico, que organiza como un sistema categorial. En este, la visión del Cosmos se divide en Cosmos abstracto y Cosmos concreto (o Cosmos pensado y Cosmos vivido). El Cosmos abstracto se representa de modo extenso (en Números, Espacio, Objetos y Mecánica), mientras que el 
Cosmos concreto de modo intenso (en Acciones, Sensaciones, Organismos y Vitalidad). Las primeras categorías son extensidades o de espacialización, las segundas, intensidades o de temporalización (1941, 89-104).

Principalmente, los puntos de apoyo teóricos son la crítica al determinismo de Bergson $^{3}$ y el exitoso texto entonces de Alexis Carrel, L'homme cet Inconnu, que Pemartín elogiará en muchas ocasiones. Considerando que los senderos de la filosofía europea caminan en un sentido anti-idealista, con su particular y salvaje -es decir, no amaestrada académicamente- visión de la Historia de la Filosofía, Pemartín establece tres épocas distintas de la misma en función de la visión del mundo predominante. En el mundo antiguo hubo un pensamiento sobre “cosas” y fijista, estático, por lo que se puede hablar del periodo como el de la Stasis griega. Por otro lado, con la edad moderna y el cartesianismo llega el tiempo de la Diástasis, donde el mundo de las cosas concretas se sustituye por un espacio geométrico o extenso igualmente estático, periodo que culmina con Einstein. Ya en la Conferencia 12 Pemartín considera que en la actualidad había un grupo de pensadores europeos que iban más allá de la actitud estática idealista y racionalista, y que protagonizaban una Metástasis del pensamiento de Occidente. Un rasgo definitorio de este nuevo camino sería una mayor amplitud en su base gnoseológica, que no se reduce a la razón científica (1941, 177). Frente al pensamiento que ha marcado la modernidad, la filosofía que representan Husserl, Scheler o Heidegger, con el antecedente de Bergson, se trata de una Filosofía de lo Concreto, de la Acción y de lo Temporal. Así, la distinción de Bergson entre intuición espiritual e intuición discursiva es señal de un campo de conocimiento que rebasa la gnoseología intelectualista y lógicoformal, pero lo importante se debe a la fenomenología alemana y la reducción fenomenológica de Husserl al ampliar la base de la ideación (1941, p.178), “porque esta búsqueda de las esencias la realiza directamente, intuitivamente, por el contacto

3 Para el filósofo francés el positivismo prescinde de la noción de tiempo o la reduce a una forma de espacio, por ejemplo, al estudiar los hechos de conciencia como si fuesen hechos exteriores o inertes, midiéndolos de modo cuantitativo y ordenándolos mediante sucesión, al modo de como se ordena algo espacialmente. Así, distingue entre el tiempo espacializado en tanto que medido convencionalmente por la ciencia, por tanto, objetivo, extenso y cuantitativo, y un tiempo auténtico que es el de la duración, el cual es irreversible, creador y cualitativo, sólo accesible mediante la intuición o vivencia de la conciencia (Bergson, 1922/2004). 
inmediato con las vivencias concretas; evitando toda orientación constructiva previa, todo análisis meramente lógica-formal”, extendiendo el contenido o materia en su capa vital, lo que ha posibilitado a Scheler o Heidegger extender la base de su análisis a lo emocional, lo personal, lo social y lo existencial. Por último, Pemartín considera que Heidegger en su "Fenomenología de lo Existencial" se aparta de la actitud idealista de Husserl para volver a la Intuición Vital de Bergson, pero amplificada. Por otro lado, para nuestro filósofo mundano, el estilo de filosofar del momento es agustiniano (1941, p.178179): "El hombre, la persona humana, aparece, para el pensamiento cientifista moderno, sobre todo del siglo XIX, como aislado, perdido, en el Cosmos" mientras que "la nueva filosofía hace verdaderamente al hombre el centro del mundo" . Lo es como conciencia intencional en Husserl y el psicologismo de Bergson, el emocionalismo de Scheler, en el Idealismo ontológico de Blondel y en el existencialismo de Heidegger, cuyo punto de partida es la hermenéutica de la existencia humana.

La Metástasis también trae una filosofía de lo concreto, pues se busca un punto de partida (1941, p. 180) “más directo, más óntico, más lleno de ser que la base gnoseológica de la Filosofía clásica, especialmente más que todo el vacío racionalismo cartesiano y sus derivados del siglo XIX”. Y por último, una filosofía de la acción. El ser o la esencia que se considera en concreto es un "ser activo", en movimiento y actividad continua, tal y como defiende Whitehead en Process and Reality (1929). Pemartín defiende por tanto una consideración dinámica de toda la realidad.

Para la fundamentación de una ontología de lo temporal que considera necesaria para salvar del relativismo moral a todo el orbe occidental, pues solamente en ella debe de fundamentarse toda moral y toda política, el punto de partida sería el ser existencial humano orientado hacia una dimensión temporal, del "darse cuenta honda y constantemente de que se es temporal" (1941, p. 184). El Espacio se considera un Tiempo completamente extendido, un "no ser", en tanto que material, respecto al tiempo humano, y este, vinculado con un tiempo divino que es en el que estaremos unidos con Dios en lo que se llama Eternidad. Como consecuencia, la materialidad espacial del mundo es concebida como una "mínima realidad negativa", como una privación de ser u obstáculo, que impide que el hombre desenvuelva su temporalidad causal y libre. El 
espacio es un "no ser” o lo que es lo mismo, un “no tiempo”. Así, (1941, p. 186) “el hombre sólo puede realizar sus destinos en el tiempo desespacializándose, despreocupándose de este inmenso mundo material, de tan escasa densidad de ser, que nos entorpece, sin embargo, como un lastre, como corteza de barro, como una prisión...”. El tiempo espiritual del hombre es reflejo del tiempo divino, y ahí reside una correcta apreciación de cómo es en la duración donde debe de desenvolverse ${ }^{4}$.

\section{Conclusiones}

Pemartín ocupará el cargo de Director general de enseñanza media y universitaria en el primer gobierno de Franco y en colaboración con Sáinz Rodríguez diseñará la Ley de Bachillerato de 1938 (Canales 2012, 65-84). Tendrá además un papel directo en la asignación del profesorado de secundaria y de Universidad tras las purgas y el exilio, hasta su dimisión por motivos políticos en verano de 1942. Desde entonces, paralelamente a una actividad semi-clandestina volcada en la vuelta de la monarquía, desarrollará una intensa actividad como conferenciante y articulista, y publica una serie de trabajos -en la Revista de filosofía y Arbor, del C.S.I.C.- destinados mayormente a comentar novedades de la Filosofía de la Ciencia internacional. En los mismos trató de establecer los fundamentos de una ontología de lo temporal de orientación realista, la cual no llegó a concluir en una obra definitiva.

Vinculado desde sus comienzos al Instituto de Filosofía “Luis Vives”, a finales de los años cuarenta participó en algunos congresos internacionales y animó la creación de la Sociedad Española de Filosofía, que tuvo en la presidencia a Zaragüeta y a Manuel Mindán como secretario, y en la que ocupó el puesto de vocal junto a Millán Puelles o López-Aranguren. Fue en la S.E.F. donde se creó en febrero de 1950 una Sección de Filosofía de la Ciencia y en diciembre, el C.S.I.C. crearía a su vez una de Filosofía e

4 Bergson remitió la posición dualista de sus primeros textos -que después modificó- a Descartes y su superposición del determinismo respecto a los fenómenos físicos al indeterminismo de la libertad humana, esto es, el de la Duración. Siendo esta creación continua, dicho tiempo auténtico se sitúa también en Dios (Bergson 1907/1973, p. 298-299) que "renueva sin cesar el acto creador y que, siendo así tangente al tiempo y al devenir, los sostiene y les comunica necesariamente algo de su absoluta realidad". 
Historia de la Ciencia con la presidencia de Rey Pastor y la secretaría de Carlos Paris, a quien seguirá Sánchez Mazas. Pemartín, que contaba con 62 años y participaba eventualmente en sesiones de ambos foros, hacía así su contribución por formalizar los estudios de epistemología y filosofía de la ciencia en España, pues de esta iniciativa surgirá la revista Theoría (Ronzón 1983, 9-40), en cuyo primer número escribirá.

En conclusión, una parte de la filosofía española de mitad del siglo XX tuvo en la atención a la crisis de la física clásica como algo fundamental, lo cual iba en paralelo de una plena conciencia de la crisis de la razón moderna o cartesiana que, ante el auge del positivismo y la autonomización de las ciencias sociales, se llevaba por delante a la propia filosofía. La crisis de la modernidad fue utilizada en la lucha ideológica contra el liberalismo y el socialismo por los sectores conservadores o semi-reaccionarios que pervivían en España, que se resistían a la democracia y coincidían por su derrumbe con el emergente fascismo. Aquellos tuvieron una posición subordinada intelectualmente a las redes liberales de Ortega o Marañón y a las Facultades de Filosofía de Madrid o Barcelona, pero contaban con un público propio preocupado por el acoso al Orden tradicional a manos de las leyes republicanas y la extensión del laicismo. Será la Guerra Civil la que haga que la mayoría de pensadores vinculados a la Iglesia o a dichos círculos de la extrema derecha disparen su carrera académica y de hecho desplacen de los centros universitarios de producción filosófica a las redes dominantes anteriores imponiendo una visión concreta de la filosofía, esto es, la de orientación y formas escolásticas, lo que va a tener consecuencias a largo plazo respecto a cómo se ha entendido de modo predominante la actividad filosófica académica en España (Moreno, 2013). Del mismo modo y como dio cuenta el propio Ortega, escolástica y tomismo no se deben de confundir, la producción teórica de Pemartín muestra hasta qué punto el pensamiento ultra-montano de entre-guerras estaba caracterizado por la huella del modernismo religioso de comienzos de siglo y la reacción neo-tomista de Lovaina. Esto lo caracterizaba por la apertura temática hacia las novedades filosóficas y científicas que marcaban la cultura de su tiempo, codificando una especie de modernismo reaccionario que mantuvo su espacio de actividad y difusión filosófica en los primeros años del Régimen franquista. Distinguiendo entre la filosofía que se enseñaba en seminarios y en 
institutos de bachillerato con la que se daba lugar en el ámbito de la investigación y publicación en la etapa autárquica del franquismo, el supuesto tomismo que dominó esta era una filosofía temáticamente abierta que dialogaba con Bergson, Marcel o Heidegger, pero abierta en tanto que mecanismo de incorporación de esas reflexiones al realismo ontológico y a formas des-historizadas, es decir, escolásticas, de actividad filosófica, como muy bien ejemplifica la tesis doctoral de Ángel González (Moreno 2013, 131-141). La actitud representada en los 1940 por Zaragüeta, Mindán, Leopoldo-Eulogio Palacios o Eugenio Frutos era capaz, sin abandonar el marco de la filosofía oficial y los lugares privilegiados del campo académico, de dialogar en plena posguerra con los que se sentían herederos de Ortega (Vázquez 2009, 126) y supone una brecha en las representaciones aún bien asentadas del integrismo que copó el campo académico español en general, y el filosófico en particular. Es más, sin ese sesgo "modernista” abierto antes de la Guerra Civil -como se ha ejemplificado con la producción filosófica de Pemartín en los años treinta con su asimilación por ejemplo de Bergson y de la filosofía de la ciencia francesano se puede entender buena parte de la filosofía española de los últimos cincuenta años cuando esta poco a poco abandone su carácter reaccionario y se ramifique en alguna modalidad de espiritualismo cristiano, colabore en asentar el carácter anti-positivista de una parte de la filosofía española posterior o prepare la recepción de la escuela cualitativista de sociología (Moreno 2008).

En cuanto a Pemartín, igual que hizo en los años treinta, la atención a los problemas fundamentales de la Filosofía y de la Ciencia de su tiempo en cuanto a los retos que suponían para el catolicismo le llevaron a seguir atento a las novedades de la filosofía europea durante la década de los cuarenta, y la extendida censura -y seguramente, su posición dentro de las facciones dominantes en la sociedad y la vida académica- no le impedirá escribir y publicar acerca de Whitehead, Maritain, Madariaga o Santayana, autores de dudosa aceptación por parte del régimen, igual que citará habitualmente la obra de Ortega desde las páginas de $A B C$. Así, si en la posguerra hubo cierta riqueza filosófica producida por algunos ámbitos vinculados a la filosofía anterior -destacando el círculo de falangistas intelectuales ligados a Zubiri-, era porque campo político y campo filosófico podían transcurrir relativamente por separado y en estos años 
se continuó tratando problemas abiertos antes de la guerra, no solamente porque algunos de los filósofos que se acomodan con la dictadura se han socializado en redes intelectuales comunes con los republicanos, sino porque los autores de referencia de los que parten también son comunes, así como los problemas de los que se ocupan. Por ello, hay que tener en cuenta que mantener únicamente la perspectiva de la ruptura y el erial impide calibrar de qué modo pervivieron y mutaron problemáticas filosóficas abiertas con anterioridad a 1936.

Por último, investigar la trayectoria de Pemartín no solamente ayuda a pensar cuales eran los basamentos filosóficos del movimiento político que alentó la Guerra Civil y legitimó la dictadura militar de Franco más allá de las explicaciones habitualmente simplistas de los orígenes y claves reproductivas del nacional-catolicismo, sino que a su vez se genera conocimiento sobre la repercusión real e inmediata de los mejores filósofos de su tiempo.

\section{Bibliografía}

BERGSON, H. (1907/1973). La evolución creadora, Madrid: Espasa-Calpe.

- (1922/2004). Duración y simultaneidad (A propósito de la teoría de Einstein), Buenos Aires: P.U.F.

CANAles, A.F. (2012). "Pemartín y la frustrada fascistiszación de la enseñanza media de posguerra”, Historia Social 74, pp. 65-84.

COROMinAs, J., ALBERT ViCEns, J. (2006). X. Zubiri: La soledad sonora, Madrid: Taurus.

GARCÍA BACCA, J.D. (2000). Confesiones. Autobiografía íntima y exterior, Barcelona: Anthropos. GARCía Sierra, P. (1993). “La evolución filosófica e ideológica de la AEPC (1908-1979)”, El Basilisco nº15, pp. 49-81

GLICK, T. F. (2005). Einstein y los españoles: ciencia y sociedad en la España de entreguerras, Madrid: CSIC.

GONZÁlez CUEVAS, P. C. (1998). ACCIÓN ESPAÑOLA. Teología política y nacionalismo autoritario en España (1913-1936), Madrid: Tecnos. 
Moreno GonzÁLEz, A. (2006).“Atomismo y energetismo. Controversia científica a finales del siglo XIX”, Enseñanza de las ciencias 24 (3).

MoRenO PESTAÑA, J.L. (2008). Filosofía y sociología en Jesús Ibáñez. Genealogía de un pensador crítico, Madrid: Siglo XXI.

- (2013). La norma de la filosofía. La configuración del patrón filosófico español tras la Guerra Civil, Madrid: Biblioteca Nueva.

LACAU ST GUILLY, C. (2010). Une histoire contrariée du bergsonisme en Espagne (1889-1920), Paris: Université de Paris III.

ORTEGA y GASSET, J. (1923/2006). El Tema de nuestro tiempo, Madrid: Alianza.

Pemartín, J. (1932ab/1933cde). “La Física y el Espíritu”, Acción Española 18/32.

- (1937/1941). Introducción a una filosofía de lo temporal. Doce lecciones sobre EspacioTiempo-Causalidad, Madrid: Espasa- Calpe.

- (1944). “Epígonos” de la era cartesiana”, Revista de Filosofía 10/11, pp. 435-467

- (1946). “Sobre el tiempo. Una nueva teoría de la relatividad”, Revista de Filosofía 18, pp. 476-497.

QUIROGA FERNÁNDEZ DE SOTO, A. (2008). Los orígenes del nacionalcatolicismo. José Pemartín y la Dictadura de Primo de Rivera, Granada: Comares.

RONZÓN, E. (1983). “La revista Theoría y los orígenes de la filosofía de la ciencia en España”, El Basilisco 14, pp. 9-40.

VÁzQUEZ GARCÍA, F. (2009). La filosofía española. Herederos y pretendientes. Una lectura sociológica (1963-1990), Madrid: Abada.

- (2013). “La primera recepción española de la epistemología histórica francesa: Gaston Bachelard” Theoría 28 (2013), 2, pp. 303-327.

ZAMORA BONILla, J. (2005). "El impulso orteguiano de la ciencia española”, Circunstancia [Internet] Enero 2005, 6. Disponible $<$ http://www.ortegaygasset.edu/fog/ver/354/circunstancia/ano-iii---numero-6---enero2005/ensayos/el-impulso-orteguiano-de-la-ciencia-espanola> [acceso el 9 de agosto de 2012]

ZARAGÜETA, J. (1934). “Perspectiva actual para una filosofía crítica”, Madrid, 1934. (Separata) 
- (1963). Estudios filosóficos, Madrid: Instituto Luis Vives de Filosofía (CSIC).

Recibido: 7/02/2013

Aceptado: 8/05/2013 